\title{
O DIREITO À LITERATURA NA ESCOLA: PROVOCAÇÕES E OUTROS OUEFAZERES
}

THE RIGHT TO LITERATURE IN SCHOOL: PROVOCATIONS AND OTHER WONDERINGS

André Magri Ribeiro de Melo*

*andre.letraslp@gmail.com

Doutorando em Estudos Literários: Literatura Brasileira pelo

Universidade Federal de Minas Gerais (UFMG). Mestre em Educação

Universidade Federal de Minas Gerais (UFMG). Mestre em Educaçăo
e Linguagem (UFMG). Especialista em Literatura e Ensino (IFRN).

Licenciado em Letras com habilitação em Língua Portuguesa e suas

respectivas Literaturas (UERN).

RESUMO: O ensaio tem como escopo as relações entre literatura e ensino com: Oenfase nas contribuiçós que os en linguagens e mediacõos pedagógicas podem opor de juvizar à formação diálovo do questõ do questos eprovos do Les caras a jos Estudos culturas contemporaneos e aos Esturas do

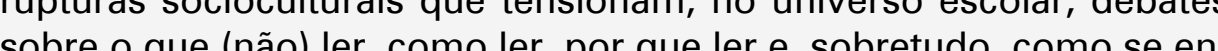
sobre o que (não) ler, como ler, por que ler e, sobretudo, como se enletramento literário no ensino médio a partir de Triste Fim de Policarpo Cuaresma, roman nó mo Quaresma, rom Barreto.

PALAVRAS-CHAVE: literatura e ensino; letramento literário; ensino médio.

ABSTRACT: The scope of this essay is the relationship between literature and teaching It empha counter between differt languages and pedagogical mediations and how they may ente the formation of young readers of literature. The main main goal is to discuss, as a horizon of understanding, some issues bockround relies on interrogat texts, school and young learners. It dies and ciecultural bro clocultur breakas which cause tent), to read, how to read, why to along with discussions about what (nol) to read, how to read, why to the text, manly, how to teach someone to read. At the final section of cy in high school through the novel Triste fim de Policarpo Our ileraa pre-igh scho the

KEYWORDS: literature and teaching; literary literacy; high school. 
1. COMPAGNON. Literatura para quê?

\section{LITERATURA: SABERES EM MOVIMENTO}

Em 30 de novembro de 2006, por ocasião da abertura dos cursos da nova cátedra de literatura do Collège de France, Compagnon recorreu a interrogações modernas sobre a função da literatura para realizar sua conferência. Trazendo à tona a tensão secular entre antigos e modernos, que se manifestou no tempo por meio de diferentes acepções, que vão desde história (filologia) versus teoria (retórica), incluindo debates que se acentuaram na pós-modernidade, como as relações entre texto e contexto/ a utor e leitor, ele defende que os estudos literários devem e podem ajudar a reorientar o debate sobre as rupturas históricas entre forma e sentido, interpretadas por alguns como desavenças entre a literatura e outras humanidades.

$\mathrm{Na}$ visão dele, ao lidar com a literatura precisamos considerar a relevância da discussão histórica e teórica, mas não apenas do ponto de vista da história como reminiscência clássica e da teoria como advento romântico, e sim como polos não doutrinários e interdependentes. Teoria deverá significar preocupação com noções elementares dos estudos literários, ilustração das limitações e contradições de qualquer investigação ou, ainda, um estado perma nente de perplexidade quanto a aspectos e problemas metodológicos. Por sua vez, a história deverá trazer consigo a dessacralização das cronologias e quadros literários, cedendo atenção superior aos contextos espaçotemporais, às alteridades alternativas e, consequentemente, ao que ele chama de prudência deontológica.

Compagnon acrescenta um terceiro elemento à gênese dos estudos literários: a crítica. Os dois elementos canonizados pela tensão entre si passam a ser costurados em volta daquilo que lhes dá razão de ser. As linhas da teoria, da história e da crítica passam a ser indispensáveis para costurar um estudo literário ou para que se estabeleçam, com ele, relações concretas que considerem seus sentidos. Essa hélice tripla nos dá condição de ver a literatura de forma a mpliada, menos sectária, como a arte de dizer, tal qual defendia Proust: "somente pela arte podemos sair de nós mesmos, saber o que enxerga outra pessoa desse universo que não é igual ao nosso, e cujas paisagens permaneceriam tão ignoradas de nós como as por acaso existentes na lua”. 2

A posição de Proust não engloba apenas a literatura e, nos primeiros anos do século XXI, é imprescindível tensionar as discussões sobre o estatuto quase sagrado que se imputa ao texto literário, por vezes apontado pela tradição humanista, não sem equívocos, como a mais genuína manifestação artística da humanidade, assertiva questionável desde a modernidade e constantemente desconstruída por filosofias da diferença e pela crítica cultural contemporânea. A possibilidade de, por meio da arte, ir ao encontro do outro e, aí,
2. PROUST. Em busca do tempo perdido, tomo III, p. 683

Ensino de Literatura 
se redescobrir, não é exclusiva da litera tura, sendo também realizável por meio de outras diferentes linguagens e artes.

O cinema, a pintura, a música, a escultura - todos constituem formas de arte que, como a literatura, asseguram parte importante da sua realização na contemplação estética e podem oportunizar experiências de alteridade. Aliás, é prudente reconhecer que em nossos tempos tal realização da arte se dá para além da contemplação, mas especialmente na interação que sujeitos e obras estabelecem entre si por meio de diferentes gêneros, suportes, linguagens e mediações informados histórica, social e culturalmente.

Falar de literatura, há algumas décadas, tem deixado cada vez mais de ser uma questão de manutenção de aristocracias elitistas letradas e supostamente universais para se engendrar como luta pelas diferentes humanidades e agenciamentos dos leitores e suas experiências, pela possibilidade de reinvenção da coletividade como a málga ma de diferenças e pela desconstrução da universalidade ocidental como parâmetro global, premissas que podemos atribuir à expansão da teoria e da crítica literária centradas no pós-estruturalismo, nos estudos culturais e em outros movimentos emergentes epistêmicos pós-virada linguística, como a crítica feminista, os estudos queer e as teorias críticas étnico-raciais que têm contribuído para que os vidro do espelhamento colonial seja m trincados e estilhaçados.
Sobre o ato de ler, Compagnon declara que lemos mesmo que isso não seja indispensável à existência porque a leitura tornaria a vida de quem lê mais cômoda, objetiva e abrangente. E prossegue dizendo que a vida consegue ser mais simples quando somos capazes de ler não apenas informações e instruções, mas o texto literá rio. Pa rece-me, porém, que, contrariando o crítico, a leitura, em seu limiar de criticidade, expõe o leitor a infindáveis incômodos e complexidades, pois o abre às possibilidades, ao entrecruzamento de posições, discursos e práticas que podem, com isso, ampliar suas condições de participação e reinvenção nas dobras do viver. Assim, concebo a leitura - sobretudo, literária - como uma forma de cifrar e decifrar o mundo, uma (des)ordem do discurso forjada na experiência e na fissuração da realidade sem, dessa forma, alçar-se à condição de melhor ou mais legítima arte, sob pena de ocultar diferentes formatos de sociabilidade que descentralizam os sistemas alfa béticos, as noções ocidentais de escrita e grafia e o próprio conceito clássico de literatura.

Nesse diálogo, estou em estreita relação com a posição adotada por Freire em $A$ importância do ato de ler, onde ele concebe a leitura como um processo de compreensão crítica que não se limita à decodificação pura da palavra escrita, mas que antecede e se expande nas cognoscibilidades do mundo. Esse pressuposto incide sobre a ideia de leitura como operação linear e autônoma, que se vê exposta à

MELO. 0 direito à literatura na escola: provocações e outros quefazeres P. 209-235 
sua principal limitação: a de não perceber que a leitura do mundo é anterior à leitura da palavra e, assim, a posterior leitura do escrito não pode prescindir da continuidade da leitura do vivido. Linguagem e realidade se prendem e se movimentam dina micamente, tal qual os espectros pluricromáticos de um caleidoscópio.

A leitura literária, pelos deslocamentos, descentramentos e desestabilidades que opera nos leitores, pode encaminhá-los à fabricação de uma vida multiforme, multilinguística e interseccionada. Se a literatura não é capaz de nos tornar completos e, definitivamente, não nos serve como justificativa para alegar universalismos que enrijecem e produzem indiferenças quanto aos diferentes, talvez nos ajude a redesenhar e questionar alguns abismos da nossa existência simbólica e material ao mesmo tempo que os complexifica horizontaliza e expande. Se, por um lado, ela nos faz vulneráveis pelo artifício da palavra e, em maior escala, da linguagem; por outro lado, não nos fragiliza acritica mente, mas nos ampara com as forças do sensível ao viabilizar espaços de autocrescimento e autoconhecimento cerzidos com os fios da experiência literária.

Longe de fazer surgir o ser huma no em sua perfeição, a literatura pode nos fazer mais sensíveis ao outro à medida que nos oferece diferentes modos de ver, pensar, sentir, saber e existir. Com isso, temos a possibilidade de construir vivências menos sectárias, separatistas e indiferentes. Quem lê ou ouve literatura não pode ser tomado como melhor que quem não a lê/ouve; apenas como alguém que tem diante de si cartografias de alteridades que podem favorecer mas nunca garantir - a experiência de, pela aproximação ou pelo distanciamento, sentir o outro, ir em sua direção e, nesse processo - quem sabe - entender melhor sobre si e agir a tivamente frente às desigualdades que ojerizam as sociedades e mutilam as relações humanas.

A percepção que nos chega pela literatura se dá na subversão da palavra, evitando o fascismo da língua rechaçado por Barthes em Aula. Nesse famoso texto de inauguração da cadeira de Semiologia Literária no Collège de France, o autor definiu a ilógica fascista como a obrigação de dizer, em contraponto a certo senso comum que atribui a insígnia facínora ao ato de impedir o dizer. Nesse sentido, a literatura é reconhecida como um discurso diferente dos demais, onde é possível ouvir a língua em temporalidades e espacialidades à margem do poder. Isso não quer dizer que a literatura, seus produtores e consumidores não sejam agenciados e sofram/produzam relações de poder sobre territórios de conflitos e disputas, mas que podemos experienciar o literário como palimpsesto de saberes e discursos operantes em redes de contra-poderes ou, no mínimo, críticos do poder.
EM TESE
BELO HORIZONTE
v. 24
N. 1
JAN-ABR. 2018
MELO. 0 direito à literatura na escola: provocações e outros quefazeres
ค. 209-235

Ensino de Literatura 
Pensar a literatura a partir do seu caráter libertário não é lhe aprisionar na vestimenta ideológica do século das luzes e da noção colonial de modernidade como momento abstrato da história e construído exclusiva mente pela Europa e sob suas bases e conceitos. Pelo contrário, os textos literários, em especial as literaturas pós-coloniais e contemporâneas, reivindicam o direito a se despir diante de qualquer tentativa de enquadramento, resistindo às a marras da colonialidade que ainda se impõem sobre nós, brasileiros, e insistem no apagamento do que nos identifica e nos diferencia. Esse tipo de poética toma a vida como referente, centros de saber alternativos às hegemonias vigentes.

Ao passo que nos dá elementos que nos inscrevem no interior de comunidades e coletivos, a literatura ta mbém nos apresenta à diferença, pois, pensada como território, distancia-se da definição de terreno fixo e atemporal; sendo composta por fronteiras movediças, contínuas descontinuidades, emergências e deformações, não subsiste esotericamente no plano etéreo das abstrações. Não é próprio do texto literário se deixar fisgar pela procura de um centro que o circunscreva. Ele é da (des)ordem dos movimentos contrários e dissidentes, se sobrepõe à definição, afeiçoa-se mais à noção de conceito como ca mpo de questionamentos, lutas e demandas, um complexo de entrelugares tão instáveis e intercultura is quanto as formações identitárias e o próprio leitor contemporâneo.
Ao evocar os possíveis valores da literatura para a formação humana é indispensável refletir sobre o acesso e a leitura do texto literário como direito humano, premissa defendida por Candido no seu famoso ensaio "O direito à literatura”, que compõe a coletânea Vários escritos. O sociólogo nos informa das relações entre direitos humanos, sua garantia e a vida das pessoas, defendendo ser necessário que se faça uma distinção entre bens compressíveis e bens incompressíveis quando pensamos no que deve, ou não, estar na ordem do que é basilar para os seres humanos e qual o lugar ocupado pela litera tura nessa discussão. Apesar da fronteira entre a mbos ser tênue e não fixa tendo em vista que os critérios de incompressibilidade são organizados e instituídos pelas sociedades no decorrer do tempo e de acordo com suas culturas - pode-se falar dos primeiros bens como os de necessidade universal e urgente: água, alimento, medica mentos. Os outros seriam acessórios: cosméticos, roupas supérfluas, joias.

Parto da ideia de que não há vida humana sem literatura. Melhor dizendo: não há vida humana sem fabulação ou imaginação, dado que o conceito de literatura como o conhecemos e em geral o discutimos é uma invenção recente que corresponde a tempos histórico-sociais e culturais específicos e não universais. Por outro lado, fabular e imaginar são necessidades antropológicas milenares tão necessárias à vida quanto a capacidade de narrar(-se), inclusive porque,

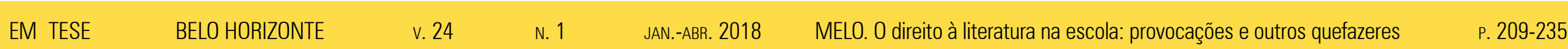


a té hoje, não se tem notícias de nenhum povo que viva ou tenha vivido sem cantos, histórias, mitos, lendas, narrativas ou qualquer tipo de poética. Suponho, então, que seja um ponto já estável que a literatura é um direito e um bem compressível, de primeira instância, que não pode ser negado e do qua ninguém pode ser privado, cultural ou institucionalmente.

A litera tura, cuja matéria principal de revelação ou ocultação é a palavra, nos permite conhecer; não do ponto de vista meramente instrucional ou informativo, mas conhecer inserindo algo no real, deformando-o, refigurando-o, desterritorializando-o - no sentido de lhe retirar qualque certeza, base ou funda mento - e reterritorializa ndo-o - no sentido de lhe imprimir novas lentes de leitura pautadas sobre dúvidas, raízes flutuantes e noções em constante transformação e autointerrogação. Ela nos cede o direito de interagir com a realidade, modificando-a, a firmando sua diversidade e tornando-a mais sensível.

Em contraste com o que certo tipo de discurso escolar geralmente preconiza sobre o texto literário, sua leitura não é uma experiência inofensiva e livre de problemas, nem conformada com a transmissão acrítica de valores ou conhecimentos. É um equívoco retumbante falar em defesa da formação de leitores literários críticos se pautando em discursos falaciosos, despolitizados e redutores sobre o ato de ler e a própria literatura, quase como se a mbos estivessem limitados a nos descolar inofensiva mente do real e, por alguns momentos, nos entorpecer de uma alegria obtusa. Ler é um trabalho árduo, que requer conhecimentos históricos e socioculturais, relaciona mento denso no confronto com o texto literário e suas teias de sentido, além de disposições psíquicas e neurobiológicas específicas.

A literatura borra, mas também elucida os paradoxos globais e locais das humanidades que a produzem e a leem/ ouvem. Não há previsibilidade na litera tura, pelo menos não naquela que realmente é passível de deslocar, de deformar algo em nós e no nosso mundo, como sugere Kafka, citado por Larrosa em Sobre la experiência, quando diz que um livro deve ser o machado que quebra o mar gelado em nós. O texto literário é devir, é a vida que a travessa o vivível e o vivido, se estabelecendo em meios, serpentea ndo entre extremos, que se expande para o ina tingível enqua nto está diante de nós. Passeia pela diferença e se constitui como terceira margem, rio que não começa nem finda, que dissipa seus limites e só é capaz de fomentar sentidos no meio, nos entrelugares, nos não-lugares, em trânsito.

\section{LITERATURA NA ESCOLA: EDUCAÇÃO DAS} SENSIBILIDADES

A literatura partilha conosco cotidianos e excepcionalidades. Mas é a imersão nas diferentes obras, escritas ou

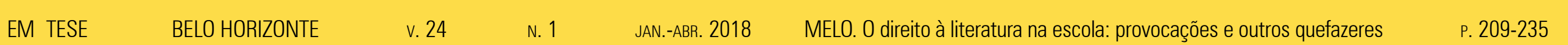


não, que as múltiplas experiências humanas acumuladas e reinventadas ao longo dos milênios, dias, horas e minutos têm nos proporcionado, que poderá fabricar linhas de fuga do establishment enquanto simulacro e nos dar frestas de saber que nos levem às paisagens artístico-literárias da linguagem.

A escola pública é um dos espaços de desvelamento do texto literário, sobretudo para a grande parte das crianças e jovens brasileiros que, filhos de mães e pais trabalhadores espoliados dentro de um sistema político-econômico-epistêmico dominador e abusivo, têm suas possibilidades de acesso e convívio com certos bens culturais (como livros, e-books, soundbooks e outros) agudamente comprometidas, quando não a niquiladas.

Para milhões de brasileiros, a escola é o espaço de encontro com a literatura (em especial, a escrita). Na contramão desse fato, certos debates pouco produtivos e, por vezes, enviesados e elitistas, questionam a necessidade de seu ensino na escola. Por isso, é preciso que nos posicionemos frente ao desafio permanente de pensar caminhos coerentes e politicamente situados para que mais crianças, jovens, adultos e idosos possa $\mathrm{m}$ ser favorecidos pelos benefícios biopsicossociais e afetivos que as experiências literárias podem desencadear e maximizar em seus itinerários formativos.
Não se pode rechaçar o ensino da literatura, que é tão indispensável à formação dos sujeitos, especialmente num país que negou o direito à educação para milhões de pessoas não alfabetizadas, revelando um dos principais efeitos das desigualdades socioeconômicas que vigoram há séculos no Brasil. As obras literárias são est(éticas) à disposição da reflexão e da contra-assinatura dos leitores, pensada nos termos derridianos presentes em "Signature, Event, Context", tendo em vista que toda assinatura de autoria oferece dobras infindáveis de compreensão e produção da linguagem a partir do momento que o texto é finalizado pelo escritor e descortinado e reinventado por quem o lê. $\mathrm{O}$ ensino de literatura deveria preconizar a apreensão da beleza, ou melhor, a sua apreciação. Porém, esse é um objetivo pedagógico realizável? Materializado em risco no processo de ensino da literatura, o prazer est(ético) não pode ser ensinado normativamente; não só porque esse é um horizonte impraticável, mas também por ser eticamente questionável.

De acordo com Jouve, em Por que estudar literatura?, é inútil todo esforço de pedagogizar o sentimento pelo belo, haja visto que ele pode ser produzido frente a qualquer objeto e a todo momento. Para experienciá-lo, ninguém necessitaria de mediações estritamente didático-pedagógicas. Há uma demanda que precisa ser satisfeita, nesse debate, com a intenção de coibir erros na abordagem da relação

\begin{tabular}{|c|c|c|}
\hline EM TESE & BELO HORIZONTE & v. 24 \\
\hline
\end{tabular}


da literatura com o ensino, que é essencial para que o texto literário se concretize como direito na vida social, cultural histórica e política - mas não só - das pessoas.

As perguntas "por que ler as obras literárias?" e "por que fazê-las serem estudadas?” respondem a finalidades específicas. Quando lidamos com o ensino de literatura não é, necessariamente, nas razões para ler essa ou aquela obra literária que devería mos depositar maior interesse, mas em considerar os motivos que fomentam seu estudo, seu ensino Mais do que um profissional capaz de teorizar o texto literário, o professor precisa ser um sujeito capaz de pensar as possibilidades materiais e simbólicas do texto, as potencialidades que, no contato com os estudantes, poderão torná-los mais conscientes da sua existência, da sua relação com a história, com as diferenças e encontros culturais e os trânsitos que as trajetórias de vida deles estabelecem, ou não, com o que se lê.

No campo pedagógico, a literatura não existe apenas como realidade estética, mas principalmente como objeto de linguagem. Jouve defende que as obras literárias merecem nosso interesse porque exprimem culturas, modos de pensar e se relacionar com o mundo. Esse ponto de vista não subtrai a qualidade estética do texto, menosprezando uma das assinaturas da literatura, mas redimensiona-a no quadro do ensino para priorizar as diferentes modalidades de constituição, interlocução e intersecção de sentidos que os leitores em formação serão solicitados a construir. Nesse ponto, cabe mencionar que nos momentos em que a qualidade estética do texto estiver sendo levada em conta, não deverá ser tratada como critério absoluto nas atividades de ensino, mas enquanto fragmento daquilo que a obra representa e significa.

Dominar saberes e fazer disso possibilidade de transformação de si e do mundo é uma das especificidades do ensino. Sendo assim, ensinar literatura não é um mero trabalho de interpretação ou avaliação do texto, pois se faz necessário perceber e dar sentido às significações e representações da obra em estudo no tempo. O maior desafio é olhar para o texto nos planos cultural e antropológico, depreendendo o que ele nos diz sobre as huma nidades, assinala ndo o que era novo à época e inédito hoje. Se quase não existe o que não possa ser representado, por meio de diferentes semioses da linguagem, num texto literário, é sinal de que nele fazem morada conhecimentos e saberes que nos provocam ao seu confrontamento, identificando-os, compreendendo-os, situando-os historicamente no plano das temporalidades humanas.

Compreender os verdadeiros papéis do texto literário enquanto objeto de ensino é papel do professor, que não é apenas aquele que percebe dada variedade de informações; nem aquele que depreende ou edifica saberes a partir das

\begin{tabular}{|c|c|c|}
\hline EM & BELO HORIZONTE & v. 24 \\
\hline
\end{tabular}


informações. O professor opera movimentos de (trans)formação desses tópicos informacionais em conhecimentos sistematizados. A pedagogia do oprimido, de Freire, e os estudos sobre educação, literatura e experiência, de Larrosa, nos dispensa ram um conjunto vasto de funda mentos epistêmico-filosóficos que nos ajudam a entender que uma informação não se faz, automatica mente, conhecimento e menos ainda em saber -, pois precisa ser reapropriada pelos sujeitos em enlaces de consciência e sensibilização crítica para consigo e com os outros.

O compromisso com o outro, com a palavra oferecida pela experiência literária significa nossa própria existência no mundo a partir do conta to e do diálogo enquanto trampolins de uma ética de leitura marcada, paradoxalmente, pela diferença e pela identificação, como é possível observar no pensamento freireano sobre o ato de ler. Comprometer-se com o dizer de outrem, com o dizer artístico-literário, demanda de quem se lança a esse desafio na docência a consciência de que o amor, a harmonia, a humildade, a fé na humanidade orientada pela criticidade e pela esperança, são condicionantes da produção dialógica de sentidos entre seres humanos no tempo histórico. Tempos que são sempre outros porque assim também o são os agentes sociais que fazem a história. O diálogo ultrapas sa dicotomias porque esfumaça as fronteiras entre mundo/pessoas, ser huma no/natureza, razão/emoção, teoria/ prática, permitindo-nos captar a realidade como processo em constante devir e elaboração.

Pensar o diálogo como categoria central à práxis pedagógica do professor de literatura coloca em evidência o papel da palavra dentro dos processos de ensino, aprendizagem e formação integral. Freire compreendia a linguagem como campo interacional povoado por vozes que ganham sonoridade à medida que nos encontramos com outros sujeitos dialogicamente e esse modo de apreender a interação linguística é fundamental para promover encontros potentes entre leitores e textos literá rios dentro de espaços escolarizados. Se toda palavra serve à expressão de um em relação ao outro, como acreditava o Patrono da Educação Brasileira, é porque as palavras fazem da enunciação um território comum a locutores e interlocutores em interação verbal. Em outras palavras, ao confrontar os estudantes com obras literárias é preciso lhes convocar à percepção crítica do que leem e à possibilidade que têm diante de si para a mpliar o escopo de sua alteridade, formada não apenas pela literatura, mas também por ela.

A alteridade é um horizonte contemplado na visão de leitura freiriana e também na visada de Larrosa sobre experiência. Experienciar supõe acontecimento e um acontecer que se passa sempre na relação com o outro, posto que "não há experiência sem a aparição de um alguém, ou de

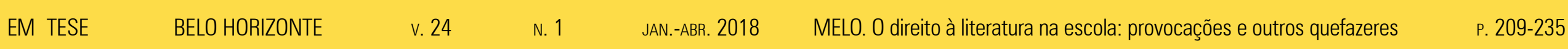


3. Tradução minha, do original: “no hay experiencia sin la aparición de un alguien, o de un algo, o de un eso, de un acontecimiento en definitiva, que es exterior a mí, extranjero a mí, que está fuera de experiência, 2006, p. 89 . um algo, ou de um isso, de um acontecimento em definitivo, que é exterior a mim, estrangeiro a mim, que está fora de mim mesmo"’. A ideia de experiência larrosiana vê no outro um elo imprescindível ao acontecimento literário pedagógica. Trata-se de um movimento de dobras sobre as quais a literatura é pedagogizada e a pedagogia é literatizada. Não há experiência generalizada que pertença a todos e a ninguém. A experiência é um acontecimento que sempre pertence a alguém, sendo vivenciada de diferentes e singulares maneiras por cada um que por ela passa.

O leitor literário que se busca formar pode ser pensado como o sujeito da experiência larrosiano: território de passagem, superfície sensível na qual algo ocorre e, passando a acontecer, deixa inevitavelmente marcas, rastros e feridas. Daí a premissa de que os sujeitos da experiência e os leitores literários não se formam apenas na atividade, mas na passividade. O estado passional é o espaço mais propenso à experiência porque se caracteriza pela abertura do indivíduo, pela capacidade de sentir e de se vulnerabilizar a ponto de experienciar. Compenetrados em nós mesmos, não há experiência, não há choque com o literário nem deslocamento pelo artístico. Por isso o seu perigo: vivenciamos elas sem proteção. E nisso está sua fortuna.

Sem o tédio, a paciência, a passividade não há como se chocar os ovos da experiência e, ao invés de coisas que nos atravessam, nós temos coisas que se perfilam, se comprimem, se expandem, mas nos tornamos dia após dia intransponíveis, incapazes de sentir. No livro Lenguage y silencio, de Steiner, há uma nota de rodapé onde consta a seguinte inscrição: "quem tenha lido A metamorfose de Kafka e possa olhar triunfante diante do espelho é capaz de ler tecnicamente as letras, mas é um analfabeto no sentido mais valioso da leitura". ${ }^{4}$ Esse leitor imune à leitura é incapaz de escrever-se, de narrar-se, posto que se indispõe à experiência e à leitura proliferadora de sentidos e afetos. $\mathrm{O}$ papel daqueles que se firmam como pontes entre leitores e textos ganha novas conotações nessa perspectiva, já que não se trata apenas de apresentar títulos ao leitor em formação, mas de atuar ativamente na produção e provocação de sentidos que desestabilizem o estudante e ajudem-no a se expor ao que pode lhe tocar.

Sem a compreensão da sua função como mediador da relação texto/leitor, o professor - e outros profissionais, como os críticos literários e estudiosos da literatura - pode incorrer em uma interpretação limitada do que é o ensino de literatura. É inegável a dimensão de fruição que envolve o texto literário e sua leitura, mas isso não significa cultivar o prazer como um produto anódino e infa ntilizado. Pelo contrário, o prazer estético é resultante de denso trabalho sobre o texto, si mesmo e o mundo, numa trama de relações que se atravessam e se conectam infinitamente.

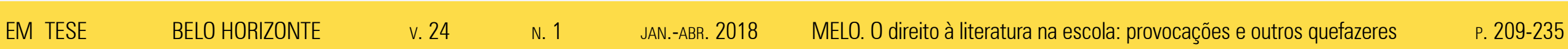

4. STEINER. Lenguaje y silencio, $\mathrm{p}$. 
Restringir as atividades de ensino a escolhas docentes ou bibliotecárias pautadas exclusivamente pelo apelo mercadológico que não raro desconsidera critérios textuais, gráficos, temáticos e editoriais - as quais julgo incontornáveis no debate sobre formação literária -, ou à livre escolha dos estudantes por intuição, ou por critérios vagos e pouco elucidativos, estará longe de contribuir para a construção de um público leitor que seja sujeito da sua experiência. As escolhas literárias precisam potencializar nos leitores em formação a capacidade de confrontar a realidade e, principalmente, a si mesmos, através da articulação entre diferentes linguagens, estéticas e éticas.

Contudo, não nego aqui o valor das escolhas individuais dos alunos ou a qualidade literária de obras aclamadas por grandes públicos e atribuídas à indústria cultural. Chamo a atenção para a reflexão crítica em torno dos processos de escolha e leitura dos textos literários na escola, que não podem ser pensados como fixos, estáveis, dados, naturais, completamente autônomos ou livres dos diferentes condicionantes sociais e culturais que, se não determinam uma educação literária, podem exercer sobre ela fortíssima influência - limitante ou expansiva. Não se trata de hierarquizar produções literárias, mas de compreender os diferente textos e os diferentes pactos firmados pelos leitores de modo que a crítica literária - ensaiada, inclusive, pelos próprios professores e alunos - integre o cotidia no de quem lê e lhe possibilite entrever por frestas dentro e fora do texto que podem ajudar a ampliar sua formação e educação literária.

A pergunta óbvia frente a essas especificidades do ensino de literatura e do professor vem à tona: de que forma proceder? Quais os meios para que o texto literário e suas significações socia is, históricas e cultura is ga nhem, de fato, mais espaço nas aulas de litera tura? São perguntas simples, mas fortes, que esboçam um problema metodológico, mas ta mbém epistemológico. Levando em consideração que, tratando de educação e literatura, não há um modus operandi absoluto, pois há quefazeres múltiplos que dão vazão à práxis pedagógica, o ensino depende do planejamento enquanto ponto chave nas situações escolares de mediação da leitura e do estudo do texto literário, ações que demandam sistematização, crítica, desconstrução e reinvenção. Há, porém, alguns locais de parada, em meio às incontáveis possibilidades de abordar o ensino de literatura na educação básica, onde julgo ser importante se deter um pouco.

Quando lidamos com o trabalho de depreender sentidos do texto literário exercita mos uma espécie de investigação arqueológica, no sentido empregado por Foucault em A arqueologia do saber, para a reorientação teórico-crítica da produção de conhecimento, que descobre diante da gente o primeiro papel do ensino, que é o de oferecer ao leitor conjuntos de saberes necessários para que textos clássicos

EM TESE BELO HORIZONTE $\quad$ V. $24 \quad$ N. 1 JAN.ABR. 2018 MELO. 0 direito à literatura na escola: provocações e outros quefazeres $\quad$ P. 209-235 

5. JOUVE. Por que estudar literatura?
p. 147 . e emergentes, antigos e contemporâneos, possam mobilizar saberes no tempo presente. A relação com os intertextos passa a ser fundamental, dada a premissa de que os sentidos da obra literária, enquanto metáforas da vida, estão de alguma forma vinculados à cultura na qual surgiram e foram utilizados, reapropriados, reinventados, silenciados, recalcados, invisibilizados. Reconstruindo esse território antropológico do texto literário, o leitor será capaz de identificar seus sentidos históricos, localizar na rrativas em disputa que o perpassam e colocá-lo em diálogo com outros campos discursivos.

Essa atividade de escavação sobre os precedentes do texto não esgota a leitura e a análise literá rias, faces do ensino de literatura, já que ele também retira seu valor dos conteúdos que antecipa e dos agenciamentos políticos dos quais participa ou é excluído. Sobre isso, Jouve diz que "uma obra passa para a posteridade quando é capaz de responder a outras questões, além daquelas que eram postas na época de sua criação", afinal, "se o valor de um texto resulta do saberes não conceitualizados que ele contém, um estudo literário 'completo' tem de dar testemunho dessa riqueza cognitiva" ${ }^{5}$ Cabe desconstruir a atemporalidade que informa a posição de Jouve, tendo em vista que a constituição de um cânone literário e de uma historiografia da literatura não se dão exclusiva mente em função de algum valor imanente dos textos e das suas qualidades formais, senão por meio de rupturas, confrontos e silenciamentos que fazem desse debate uma seara inconstante, dobrável, rugosa e não linear. As literaturas de autoria negra e feminina, ${ }^{6}$ por exemplo, são exemplos nevrálgicos das disparidades e omissões a tivamente construídas no cerne dos cânones e histórias literárias.

Ainda acerca da importância da dimensão histórico-cultural de leitura e análise do literário, Jouve defende que as obras literárias resistem à nossa reapropriação porque elas nos colocam em oposição a subjetividades e modos de compreender o mundo que não necessariamente são os nossos. Jogando em outro campo, filósofos que fizeram das suas obras espaços de profundo diálogo com a literatura, como Derrida e Deleuze, advogam em função da inevitável reapropriação dos textos literários pelo leitor como condição para que oposições e diferenças entre modos de ver e de fazer venham à tona nos processos de leitura; eles não estão interessados no aprisionamento do sentido a nenhuma estrutura lógica, mas buscam a interrogação contínua do que se arroga como lógico e reivindicam a liberação dos sentidos.

Partindo do conceito de isomorfismo que Wittgenstein desenvolve em Tractatus lógico-philosophicus, segundo o qual se a linguagem é capaz de representar o mundo isso se justifica porque há alguma correspondência entre uma expressão e aquilo que ela exprime, podemos considerar que, para uma interpretação ser coerente com o texto literário devem
6. Para um panorama crítico da literatura afro-brasileira de autoria feminina, ver: DUARTE e FONSECA. Literatura e Afrodescendência no Brasil (Vol. 1 a 4).

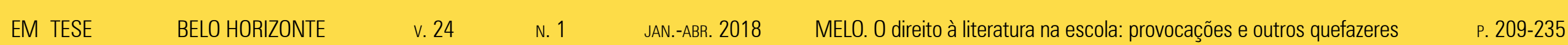


haver pontos comuns entre a imagem que o leitor faz e o texto que espelha essa representação. Essa seria, então, uma compreensão isomorfa: arquitetura de relações que correspondem entre si no objeto interpretado e na interpretação produzida a partir dele. Em outras palavras, o leitor está aberto a diversas possibilidades de ler e interpretar a literatura, desde que a materialidade e os simbolismos dos textos com os quais está em confronto e diálogo lhe permitam tais inferências, sem que se faça desse pressuposto uma justificativa para favorecer inflexões entre literatura e representação, como se o literário fosse reduzível à mera articulação de efeitos miméticos.

No ensino de literatura, ainda é o confronto com as obras o ponto mais importante de todo o processo, porque é isso que catalisa nossa experiência literária. São trajetos repletos de possibilidades que se abrem diante dos nossos objetivos como professores e das próprias necessidades daqueles para quem lecionamos e com os quais aprendemos. Os textos literários participam das nossas histórias de vida, lhes a tribuindo outros significados, aprofundando enunciações e dando voz ao inaudível.

\section{PARÂMETROS PARA A FORMAÇÃO DE JOVENS}

\section{LEITORES LITERÁRIOS}

As Orientações Curriculares para o Ensino Médio (dodo Ensino Médio - Literatura, p. 67. ravante OCEM) apontam que uma das marcas do discurso literário é a sua condição limítrofe de transgredir e reinventar fronteiras, o que pode garantir ao leitor o exercício da liberdade. O documento ainda convoca a Lei de Diretrizes e Bases da Educação, ${ }^{7}$ em seu Art. 35, Inciso III, para realçar como objetivo a ser alca nçado pelos estudantes do ensino médio o aprimora mento desses como pessoa humana, incluindo-se aí a formação ética, o desenvolvimento da autonomia intelectual e do pensamento crítico. Com a finalidade de responder a esse objetivo estabelecido nos a utos da legislação educacional nacional, as OCEM informam que o ensino de literatura na escola deve se centrar prioritariamente em formar o leitor literário, ou melhor, fomentar seu processo de letramento literário.

Sendo a leitura literária um direito dos estudantes do ensino médio previsto em orientações, diretrizes, leis e outros exemplares oficiais que se ocupam de questões curriculares, as OCEM vêm ratificar a imprescindibilidade dos conhecimentos de literatura na educação formal dos jovens. Veja-se, por exemplo, as seguintes passagens: “o texto literário é por excelência polissêmico", "por meio da leitura dá-se a concretização de sentidos múltiplos", "atenção para a dimensão dialógica do texto, [...] para sua pluralidade discursiva" 10 e "a leitura do texto literário é, pois, um acontecimento que provoca reações, estímulos, experiências múltiplas e variadas, dependendo da história de cada indivíduo". ${ }^{11}$ Todos esses excertos concentram sua
7. BRASIL. Lei no $9394 / 96$ - Diretrizes e Bases da Educação Nacional.
EM TESE
BELO HORIZONTE
v. 24
N. 1
JAN.-ABR. 2018
MELO. 0 direito à literatura na escola: provocaç̄ões e outros quefazeres
ค. $209-235$

8. BRASIL. Orientações Curriculares do Ensino Médio - Literatura, p. 60

9. BRASIL. Orientações Curriculares do Ensino Médio - Literatura, p. 65.

10. BRASIL. Orientações Curriculares do Ensino Médio-Literatura, p. 66. 
a rgumentação no texto literário enquanto possibilidade, caminho a se construir em constante conversa com outros tempos, espaços, lugares, textualidades, sujeitos.

Tem-se observado que o ensino do texto literário demanda métodos e reflexões ta mbém específicos, tendo em vista a atividade pedagógica ir além da crítica e da teoria literária. Analisar o texto literário do ponto de vista histórico-teórico demanda o conta to entre o estudioso e a obra. Ensinar literatura pede mais: mediar o processo de ensino do texto literário requer outras pessoas - texto, professor e alunos, cada um aprendiz de si e dos outros - e outros saberes e quefazeres. Essas especificidades tendem a ir se bifurcando à medida que as turmas, os estudantes e os objetivos pedagógicos vão ganhando contornos mais nítidos, o que reforça a estreita conexão entre composição curricular e sujeitos da educação.

No campo do ensino de literatura, os primeiros avanços remetem ao debate sobre concepções de literatura que, de acordo com Rouxel em "Aspectos metodológicos sobre o ensino de literatura”, apresentou três expressivas mudanças de paradigma: (I) a literatura deixa de ser entendida como corpus restrito a textos legítimos e ganha uma concepção extensiva a outras modalidades textuais; (II) a literatura passa de corpus à prática e à atividade de leitura, deslocando um interesse relativamente recente para os campos de produção, edição e recepção dos textos literários, bem como para os agentes que integram essa cadeia, como escritores, editores, críticos, leitores e, é claro, a escola; (III) a litera tura vence a concepção autotélica, que por a nos a enquadrou na finalidade estética, e passa a ser motivo de comunicação e interação, importando o seu valor existencial e o que os valores ético e estético representam e significam para diferentes agências do humano.

$\mathrm{Na}$ didática da literatura, figuram progressos em outras duas linhas que significam muito para a formação de leitores no ensino médio: a leitura literária e a cultura literária. ${ }^{12}$ A primeira passou a se pautar não mais na virtualidade do leitor modelo, mas nos leitores reais, plurais e empíricos; encontrou na interpretação dos leitores uma a tualização do texto do autor e tem combatido posturas distanciadas com posturas implicadas, defendendo o engajamento entre leitores e textos. Essa transformação da relação com o texto acaba se traduzindo, a tualmente, como uma reabilitação do valor da identificação entre quem lê e o que se lê, aspecto depreciado por muito tempo e taxado de regressão ou etnocentrismo. Provocar nos jovens leitores uma distância participativa, uma postura leitora que oscila entre a aproximação e o distanciamento continuamente, parece uma postura adequada às abordagens metodológicas para ensinar literatura no ensino médio.
12. ROUXEL. Aspectos metodológicos do ensino de literatura.

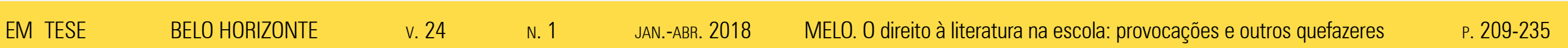


A concepção tradicional de cultura literária, circunscrita a estratégias restritas de apreensão e apropriação de um cânone que não se interrogava arqueológica e genealogicamente sobre sua formação e recepção e ignorava as reverberações da história e dos modos de viver em sua constituição vem sendo objeto de diferentes críticas. Uma delas se pauta na ideia de cultura literária como capital cultural, conforme discussão de Bourdieu em As regras da arte, que está atrelada à representação de uma espécie de inventário cumula tivo das obras legitimadas que constam em nossa história de leitor e aos valores sociais atribuídos a elas dentro de sistemas de poder forjados a partir de regras e discursos específicos, mas também por rasuras e emergências nessas estruturas. Outra visão aciona a alegoria da biblioteca interior, da qual participam nossas experiências com textos legitimados ou não, leituras materiais, virtuais ou imaginárias. Essa última percepção, cuja orientação epistêmica e política é inspirada nos estudos pós-estruturalistas, encara a cultura literária como um processo não estabelecido e passível de variações que fazem do dar a ler, do dar a escrever e do dar a ouvir práticas singulares na formação de um leitor, mesmo que contaminadas pela experiência histórica e social do seu tempo.

Ambas possuem seu valor frente ao ensino de literatura a primeira porque, pela leitura do que tem sido canonizado ao longo do tempo, é possível desconstruirmos e repensarmos nossa identidade social; e a segunda pelo fato de, por aquilo que nos invade enquanto fabulação e pela abertura à elaboração de outros imaginários e outros critérios de imaginação, nos auxiliar a construir outros parâmetros de identificação e diferenciação, questiona ndo os movimentos de legitimação de alguns textos e autores em detrimento de outros. O ponto é que a experiência de leitura emerge do sensível e provoca o leitor à reinvenção de si e à interpretação das distintas sociabilidades vigentes no horizonte histórico que partilha com outros sujeitos, sem deixar de catapultá-lo às margens do imprevisível, das contingências e do casual: traços impartíveis da experiência literária.

Estaríamos caminhando para o ensino não de literatura, mas de leitura literária? A literatura como experiência ou como objeto de dissecação histórica, teórica e crítica? $\mathrm{Na}$ verdade, quando o texto literário integra uma experiência, sua rede de histórias vem à tona tra zendo consigo a curiosidade por sua análise, que demanda conhecimentos teóricos e vai consolidando um estado de disposição à crítica, ao ensaio de dizer. Recordemos Larrosa, a partir de Tremores, ao pensar naquilo que não pode ser esquecido. E não o pode porque nos passou, nos aconteceu e nos atravessou, construindo morada em nós. A experiência pode ser pensada como isso: os acontecimentos que, mais do que viver, nos fizeram acontecer nos palcos e bastidores da vida e nos deslocaram para o contra-tempo, a contra-história, a

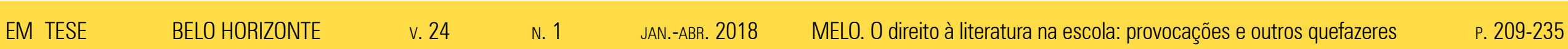


13. DALVI. Literatura na escola: propostas didático-metodológicas,
p. 69 . contra-memória, uma fresta onde a suspensão do cotidiano sinaliza o estado de poesia.

A formação de jovens leitores no ensino médio nos pede a compreensão de que qualquer posicionamento que assumimos é costurado à história e passível de consensos contrassensos. Aos professores dessa etapa da educação básica, cabe muito além da formação, da informação ou da conformação de leitores. É preciso que "possamos contribuir para que os leitores de litera tura de hoje e a manhã refutem e reinventem, provocativa, criativa e ousadamente, a leitura, a literatura e a escola que se lhes afigura". ${ }^{13}$ Falo de uma educação literária, de uma educação que encontre na literatura todo seu potencial pedagógico, que não devemos tomar no sentido de procurar no texto literário a veia positivista cara ao projeto moderno de conhecimento e sujeito, mas outra coisa: a possibilidade de aprender na experiência, descobrir o que os textos têm a dizer no contato com eles e no desvelamento das histórias que eles têm para nos contar, como na epígrafe do romance Viva o Povo Brasileiro, de João Ubaldo Ribeiro: o segredo da verdade está na consciência de que não existem fatos, só histórias. São as histórias que lemos, ouvimos e conta mos ao longo dos nossos itinerários de vida que constroem e desconstroem, em contínua descontinuidade, as verdades do mundo.
O leitor escolar que participa de processos normativos e curriculares precisa antes se descobrir como leitor empírico. Aquele leitor que todos somos. Que lê como quem sente, que divaga e fabula, que interpreta de várias formas um mesmo fato e que vive as paixões que o texto suscita nele sem medo dos riscos que há nos devaneios. $\mathrm{O}$ ato de devanear, aqui, vincula-se a uma postura hermenêutica que enlaça a poesia e a escuta como políticas que se inscrevem e transitam entre a voz e o silêncio. O leitor em devaneio se veste de Ismália, sobe a Construção de Chico Buarque, busca-se nos Becos da Memória de Conceição Evaristo e segue à procura de uma Infância que sempre devém memória porvir.

\section{ALTERIDADES EM DISPUTA: QUEFAZERES NO}

ENSINO DE LITERATURA BRASILEIRA

Nesse ponto das minhas reflexões, proponho uma sequência expandida para o letramento literário de jovens do ensino médio a partir do romance Triste fim de Policarpo Quaresma de Lima Barreto. A proposta se orienta por pressupostos didático-pedagógicos que compreendem o letramento literá rio como agência política da linguagem que permite a construção e a desconstrução literárias do real, tomando o pacto ficcional e imaginativo enquanto cerne de práticas, experiências e modalidades de leitura e produção textual específicas. A noção que adoto se inscreve nos estudos do
EM TESE
BELO HORIZONTE
v. 24
N. 1
JAN.-ABR. 2018
MELO. 0 direito à literatura na escola: provocações e outros quefazeres
ค. 209-235

Ensino de Literatura 
14. CASTANHEIRA, GREEN e DIXON. Práticas de letramento em sala de aula, p. 9.

15. CASTANHEIRA, GREEN e DIXON. Práticas de letramento em sala de aula, p. 9. letramento, termo que designa as práticas sociais de usos da linguagem que envolvem a capacidade e os conhecimentos, os processos de interação e as relações de poder relativas ao uso da escrita em contextos e meios determinados. Em linhas gerais, falo de um lugar de saber que não compreende a escrita como um fim em si mesmo, autônomo e individual, mas como experiência social e subjetiva, forjada em relações ideológicas cifradas e tramadas pela diferença.

Nesse sentido, a noção de letramento, pensada em diálogo com os estudos literários, designa fenômenos sociais e políticos que são definidos e redefinidos por contraste diferenciação, pois o significado de letra mento para qualquer grupo "torna-se visível nas ações de seus participantes, naquilo para o que esses participantes se orienta $\mathrm{m}$, nas responsabilidades que assumem ou atribuem aos outros, na aceitação ou rejeição de respostas ou no engajamento que têm com textos diversos". ${ }^{14}$

O letramento não se passa, sozinho, na cabeça do leitor e tampouco é homogêneo a ponto de ser vivido e compreendido da mesma forma por qualquer comunidade de leitores. Pelo contrário, ele é "um processo dinâmico em que o significado da ação letrada é continua mente construído e reconstruído por participantes, quando se tornam membros de um grupo social". ${ }^{15}$
Nessa perspectiva, a escolha do romance de Lima Barreto responde à necessidade ${ }^{16}$ de os alunos do ensino médio lerem textos da literatura brasileira nessa etapa da sua educação formal com a finalidade de melhor compreenderem a formação histórica e cultural do país enqua nto constroem, por meio de saberes estéticos e éticos, sentidos sobre essas experiências de conhecimento. Importante considerar que se fala, aqui, de um grande escritor afrodescendente que, por muito tempo, foi negligenciado pela crítica e historiografia literá ria brasileira, intima mente conta minadas com ranços coloniais que resultaram em visões estereotipadas $\mathrm{e}$ deturpadíssimas da literatura, dos escritores e do próprio Brasil. Letrar literaria mente o estuda nte do ensino médio a partir da leitura de Lima Barreto constitui um imperativo não só formal e artístico, como ta mbém racial e social, pois se parte da sala de aula e da escola como espaços de poder, discurso e conflito que abrem, pela leitura crítica e pelas relações de afeto suscitadas no confronto com a arte, à contestação, à ruptura e à invenção.

O atual contexto sociopolítico brasileiro, marcado pela fragilidade democrática, pelo genocídio da juventude negra, dos povos tradicionais e indígenas, bem como pela disseminação de ideá rios fascistas e autocráticos, fazem de Triste fim de Policarpo Quaresma uma leitura atual e significativa para os estudantes. Outro aspecto a ser ressaltado é que
16. O estudo da literatura brasileira tem sido citado, ao longo da historia da legislação curricular do ensino médio, como o principal criorizado no ensino de litera ser As o Ensino Médio (OCEM), no que compete aos Conhecimentos de Literatura, anontam que "se deve privilegiar como conteúdo de base no ensino médio a Literatura brasileira, porém não só com obras da tradição literária, incluindo outras, contemporâneas innificativas" (BRASIL, 2006, p. 73). No documento da Base Nacional Comum Curricular, a literatura brasileira também aparece como horizonte pedagogico a ser contemplado na area de Linguagens, Códigos e suas Tecnologias, especificamente no campo curricular artísticoliterário.A seção do documento onde constam os Parâmetros para a organização/progressão curricular informa que um dos objetivos artístico-literários do Ensino Médio é "propor a leitura de obras significativas da literatu brasileira, contextualizando produção, circulação e recepcão, produção, circulaçâo e recepção, sincrônico, ficando a critério local estabelecer ou não a abordagem do conjunto de movimentos estéticos, obras e autores, >>> 
16. $>>>$ de forma linear, crescente ou decrescente, desde que a leitura efetiva de obras selecionadas não seja prejudicada" (BRASIL, 2017, p. 514). Dentre as habilidades que se esperam dos jovens, no campo artístico-literário relacionado a práticas de leitura, está a EM13LP51, que dispõe sobre "analisar obras significativas da literatura brasileira e da literatura de outros países e povos, em especial a portuguesa, a indígena, a africana e a latino-americana, crítica literária (estrutura da composicão estitura da discursivos), considerando contexto de produção (visões de mundo, diálogos com outros textos, inserções em movimentos estéticos e culturais etc.) e 0 modo como elas dialogam com presente" (BRASIL, 2017, p. 516).

17. BRASIL. Lei 10.639/03.

18. BRASIL. Lei 11.645/08. o estudo da literatura afro-brasileira é obrigatório nas escolas de nosso país, amparado pelas Leis $10.639 / 03^{17}$ $11.645 / 08,{ }^{18}$ e a literatura, em diálogo com outras artes, é uma das bases da materialização desses marcos legais que, há quase duas décadas, vêm reorientando e movendo concepções e práticas pedagógicas no campo das experiências curriculares em espaços escolares.

Por litera tura afro-brasileira compreendo o conjunto de obras que, numa conjunção dinâmica, dialogam com cinco grandes fatores apontados por Duarte em "Literatura Afro-Brasileira: um conceito em construção" que discute com profundidade esse conceito no âmbito da teoria e da crí-tica literária contemporâneas: temática, autoria, ponto de vista, linguagem e público. Trata-se de uma literatura que compõe a literatura brasileira, mas de um outro lugar enunciativo: um território cujo projeto não é reforçar pressupostos ro-mânticos que remontam à busca do nacional como efeito universal. As interrogações que as produções literárias afro--brasileiras lançam partem de outras pautas: o reconheci-mento dos afrodescendentes como sujeitos de arte e cultura capazes de produzir saberes artístico-literários e a denún-cia/combate ao etnocentrismo e ao colonialismo - ambos calcados no racismo estrutural e epistêmico - que, desde a modernidade europeia, têm insistido em nos colocar à margem do mundo das letras e da própria civilização, ora
EM TESE
BELO HORIZONTE
v. 24
N. 1 JAN.ABR. 2018

MELO. 0 direito à literatura na escola: provocações e outros quefazeres P. 209-235

gnorando nossa condição humana, ora expondo nossos corpos negros como objetos exóticos.

Esse roteiro de leitura lida com diferentes modalidades de letramento: crítico, literário e negro. À medida que o interesse por práticas de escrita e linguagem, situadas em contextos sociais específicos e alinhavadas por determinadas relações de poder (em geral, assimétricas), nos move, a noção de literatura como força que faz girar o pêndulo da vida ganha força, especificamente no caso da afro-brasileira, cuja capacidade de nos falar com outras palavras, gestos e corpos sobre nossas identidades e diferenças é inegável. Desse ponto de vista, o letramento negro se apresenta como um território fértil para a produção de sentidos mediados por diferentes poéticas da linguagem a partir do qual são colocados em cena os afrodescendentes e suas histórias, memórias, culturas, epistemes, artes, ontologias e cosmovisões.

Em outras palavras, o letramento negro é um agenciamento sociocultural, uma política linguística e literá ria que centraliza sua especificidade na reinvenção discursiva do lugar da negritude, reivindicando a transição do negro-tema para o negro-vida, mudança paradigmática que desmonta o olhar temático, objetificante e estrangeiro sobre as populações negras e afrodescendentes e reivindica um experiências e saberes emancipatórios e empoderadores espaço outro de enunciação informado pela emergência de 
em termos artístico-literá rios, mas ta mbém sócio-históricos, culturais, econômicos e epistêmicos. Esse paradigma emergente marca a cisão irreconciliável da literatura afro-brasileira e outras artes com modelos estéticos e antiéticos, pois a palavra burilada, poetizada e trabalhada literária e artisticamente configura um ofício político e uma luta epistemológica antirracista.

A entrada de Lima Barreto e seu romance nas salas de aula de ensino médio brasileiras objetiva que uma proposta de letramento literário deve passar, necessaria mente, pelo diálogo com outras artes, sistemas semióticos e instâncias mediadoras. Por essa razão, a sequência em discussão se articula a caminhos teórico-metodológicos que consideram a cultura das mídias e o fenômeno da hipertextualidade como basilares para ampliar a compreensão dos estudantes em relação à obra principal, recorrendo a releituras, adaptações e recriações que conversem diretamente com as experiências de participação nas culturas letradas e midiáticas nas quais os educandos atuam cotidia namente.

A sequência expandida de letramento literário, inspirada nas orientações de Cosson em Letramento literário, obedece a um roteiro pré-disposto de elementos que constituem o processo de imersão na obra literária e no seu estudo: (a) motivação, que consiste em uma atividade de preparação, de introdução dos alunos no universo do livro a ser lido; (b) introdução, que é a apresentação do autor e da obra; (c) primeira leitura: convém que a leitura seja feita prioritariamente extraclasse, o professor e os alunos buscarão acertar em conjunto os prazos de finalização da leitura; (d) primeira interpretação: o objetivo dessa etapa é levar o aluno a traduzir a impressão geral do título, o impacto que ele teve sobre sua sensibilidade de leitor; (e) contextualização: compreende o aprofundamento da leitura por meio dos contextos que a obra traz consigo e passa por diferentes níveis - teórico, histórico, estilístico, poético, crítico, presentificador e temático; (f) segunda interpretação: tem por objetivo a leitura aprofundada de um de seus aspectos. Ela pode estar centrada sobre uma personagem, um tema, um traço estilístico, uma correspondência com questões contemporâneas, questões históricas etc.; (g) expansão: busca destacar as possibilidades de diálogo que toda obra articula com os textos que a precederam ou que lhes são contemporâneos ou posteriores. O trabalho da expansão é essencialmente comparativo. Trata-se de colocar duas obras, ou traços, em contraste a partir de seus pontos de convergência e divergência.

A motivação para a leitura de Triste fim de Policarpo Quaresma pode se dar a partir da visita a museus interativos ${ }^{19}$ na web que contenham documentos históricos da primeira metade do século XX no Brasil e dos últimos anos
19. Os Museus Virtuais do Império e da República são boas opçōes para iniciar a exploração dos contextos histórico, político e cultural que serviram a escrita da obra de Lima Barreto. O Museu Imperia pode ser acessado através do link: <http://www.museuimperial. gov.br/servicos-online/tour/visitainterativa.html> e o Museu da República pode ser acessado pelo link: <http://museudarepublica. museus.gov.br/visita-virtual/>.

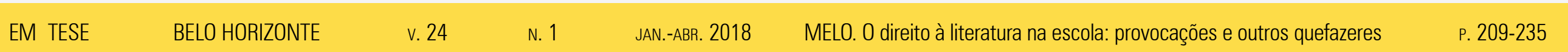


do século XIX, de modo que os alunos possam reconstituir alguns cenários políticos, sociais e culturais dos cotidianos que forneceram elementos cruciais para que Lima Barreto escrevesse o principal romance pré-modernista do país. Notícias, reportagens, recortes de jornais, documentação institucional e outros arquivos podem ser mobilizados para motivar os estudantes a perceberem seu país com as lentes da literatura e o papel central que as diferentes figuras do arquivo (museus, álbuns, bibliotecas, diários etc.) ocupam no trabalho de criação/produção literária, revelando o diálogo íntimo entre literatura, história e memória que orienta as bases de um sistema literário, suas digressões e expansões.

A apresentação da obra e do autor pode ocorrer com a partilha, junto à turma, de alguns elementos biográficos do autor e da sua obra, sem fazer desse momento um enquadramento de relações lineares e presunçosamente correspondentes entre vida e produção literária. Considerar os parâmetros da crítica (auto)biográfica contemporânea, que propõe uma leitura fragmentária, rizomática e esparsa da obra literária e do escritor, é um caminho prudente para ensinar aos jovens leitores que a vida não determina o literário, nem vice-versa, mas que a mbos partilha m de uma rede de influências mútuas que alimentam e fabricam realidades, imaginários e discursos simultânea e paralelamente.

(1)
BELO HORIZONTE

v. 24
N. 1
Pedir aos alunos que tracem relações com as primeiras informações sobre o romance e seu autor e as informações históricas e sociais às quais tiveram acesso por meio de hipertextos e de outras mídias à disposição no ciberespaço pode ser relevante para que eles iniciem o processo de sistematização dos conhecimentos que estão construindo sobre o livro escolhido para o trabalho. Ressaltar que a condição social e racial de Lima Barreto foi crucial para a materialização do seu sequestro na literatura brasileira é fundamental, inclusive porque esse fato dialoga com espaços da narrativa de Policarpo Quaresma e com a construção de novos olhares e perspectivas sobre a historiografia literá ria brasileira, iluminando o caráter conflituoso e de disputa que, em geral, é apagado ou atenuado quando se fala sobre literatura, arte e cultura no Brasil e em outras ex-colônias europeias, como se essas esferas de produção e experiência humanas fossem construções atemporais de uma humanidade branca, masculina, heterossexual, europeia e rica.

A primeira leitura e a primeira interpretação são interdependentes. Caberá ao professor elaborar com a turma um contrato didático que estabeleça os prazos de leitura e os momentos, ao longo desse processo, que serão dedicados à partilha e discussão das primeiras impressões de cada leitor na sala de aula. Priorizar o entendimento dos alunos sobre 
o título do romance, as apreensões inicia is sobre os personagens, os cenários, os conflitos e os embates políticos, sociais e culturais que dão liga à trama de Lima Barreto é o objetivo nessa etapa da sequência.

Contextualizar a obra não significa, necessariamente passar por todos os aspectos sugeridos nesse plano de leitura literária. Nessa etapa, a ênfase deve recair sobre meios e trajetos interpretativos que levem os jovens leitores a olharem e repararem no texto literário a partir de algumas perspectivas. Essas lentes podem ser conceitos de outras á reas do conhecimento que têm vinculação estreita com os estudos literários, como a sociologia, a antropologia e a filosofia; ou mesmo conceitos da própria teoria literária, como os elementos da narrativa, a caracterização dos personagens, espaços, tempos, entre outros, provocando-os a destaca rem, em especial, tensões e paradoxos entre o que é observável no romance e na sociedade brasileira, em termos de representação racial, geoespacial e política.

Há modos mais próximos da tradição moderna, a exemplo da abordagem histórica da obra, que se preocupa com sua inserção num tempo específico, e há ta mbém perspectivas mais contemporâneas, como aquelas que se preocupam com a recepção da obra e buscam reconstituir modos de le dos leitores do século passado em contraponto aos de hoje ou se interessam mais pelos dispositivos de subjetivação e dessubjetivação próprios à experiência literária de forma mais a mpla. Nessa linha, a ideia de presentificar o romance é uma proposição que costuma agradar os alunos, pois se pauta no estabelecimento de relações diretas entre a obra e contextos sociopolíticos e culturais contemporâneos a eles e às suas vivências. É o espaço ideal para lançar um convite: pensar suas histórias, o país onde vivem e os múltiplos desafios pelos quais passamos em contraponto com a obra fortalecendo um dos pressupostos essenciais dos estudos do letramento, que é a análise das práticas de linguagem para evocar interrogações e questionamentos das formas de poder constituídas e aliá-las, discursivamente, à transformação.

Diferentes temas podem ser pensados, e perguntas lançadas, a partir de Triste fim de Policarpo Quaresma para contextualizar e a mpliar a experiência literária dos jovens, como os estudos e os livros, as formas de trabalho, a situação das mulheres e as tensões entre o nacionalismo e o colonialismo. Esses assuntos têm papel singular no romance e guardam implicações fortíssimas com questões do Brasil atual, seja para confirmar que pouco tem mudado desde a época em que o livro foi escrito e lançado, seja para iniciar uma discussão que ressalte as conquistas e as mudanças que a tingiram, ao longo do tempo, a relação com os estudos, o mercado editorial, a formação de leitores, a opres-são e as violências contra as mulheres, as questões raciais,

MELO. 0 direito à literatura na escola: provocações e outros quefazeres P. 209-235 
as fronteiras entre escravidão e trabalho e as contradições entre o nacional e o colonial - todos temas fundantes nesse romance e que são excelentes chaves de leitura para pensar as implicações entre literatura e vida de maneira crítica e à parte do universalismo romântico europeu.

A segunda interpretação representa mais um avanço no trabalho de construção de sentidos pela literatura. Aqui, se espera que os estudantes possam elencar um aspecto, dentre todos que puderam conhecer ao longo da experiência, para aprofundar por meio de dissertação ou outra produção que lance mão de outras tecnologias além da escrita, ou, pelo menos, em suportes diversos. Esse aspecto pode ser um tema, um traço estilístico da narrativa, uma questão histórica, um conceito da teoria literária, da sociologia etc., que os alunos deverão desenvolver, intensificar, explorar para além da superfície e do imediatismo, revelando nuances da obra até então pouco, ou raramente, observadas na sala de aula.

Por sua vez, a expansão é uma etapa do processo que lida basicamente, com a comparação entre a obra em questão e outras, anteriores, contemporâneas ou posteriores a ela. É um elemento da sequência didática de letramento literário inspirado em funda mentos da literatura comparada, seara dos estudos literários que se vale do comparativismo entre textualidades, materialidades e discursividades para compreender e questionar aspectos que as aproximam e, sobretudo, as fazem diferentes. O que se persegue, aqui, é a ampliação dos espectros interpretativos vinculados ao romance de Lima Barreto, reitera ndo seu lugar de escritor brasileiro que, com Triste fim de Policarpo Quaresma, melhor introduziu as questões que o modernismo atacaria incisivamente a partir dos anos 1920, com a Semana de Arte Moderna e os manifestos que marcaram esse período de novos fôlegos na formação artístico-cultural do país. A presença de elementos nacionais, a crítica à herança colonial, a ruptura irrecuperável com o ideário romântico e a luta pela afirmação do genuina mente brasileiro são temáticas que podem favorecer a discussão da obra de Lima Barreto em sala de aula.

No decorrer da sequência, dentro das etapas que forem mais adequadas ao desenvolvimento do trabalho do professor, o uso de produções midiáticas tenderá a fortalecer as demais estratégias didático-pedagógicas de modo a consolidar a metodologia de ensino do texto literário e a tingir os objetivos formulados. Algumas possibilidades viáveis são a exibição do filme Triste fim de Policarpo Quaresma (1998), que retrata de forma autêntica o enredo original do livro. Além dele, outras obras cinematográficas relevantes para a compreensão das interrogações que Lima Barreto nos dispõe são Mauá - o Imperador e o Rei (1999), que se inspira na ideia de pátria sem um nacionalismo extremista; $\mathrm{e}$

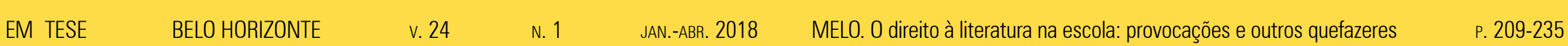


Macunaíma (1969), que é baseado no livro homônimo de Mario de Andrade (1928) e desenvolve a ideia de anti-herói brasileiro. No campo televisivo, a minissérie Chiquinha Gonzaga (1999) centra e aprofunda a luta pela afirmação da música popular brasileira e a denúncia da condição social da mulher frente a um modelo societal forjado pelo colonialismo europeu e o autorita rismo falocêntrico.

O uso de adaptações da história criada por Lima Barreto para outros formatos, enredos e suportes, como é o caso das HQs, estimula a pluralidade de concepções textuais e literárias em sala de aula, além da recorrência a textos não-literários que ofereçam, no limiar das possibilidades de contextualizar a obra na sequência expandida, imagens do autor, da sua produção e da história do país. As pesquisas que resultaram nas biografias $A$ vida de Lima Barreto (1881-1922) e Lima Barreto: um triste visionário são exemplos de notável qualidade e comprometimento sociopolítico com a reconstituição da figura de Lima e do seu legado para a literatura e a cultura nacional.

A leitura e o estudo das várias capas do livro, em suas diferentes versões, e o que elas propõem do ponto de vista gráfico, editorial e iconográfico pode despertar a curiosidade dos estudantes e abrir um campo fecundo para pensar a literatura com olhares menos grafocentrados. $\mathrm{O}$ mérito da proposição é o trabalho imagina tivo que se atrela às interpretações visuais e (re)leituras advindas daí, do campo das sensibilidades, não só intelectuais, mas afetivas, corporais e cognitivas.

Com esses encaminhamentos, partilhei sugestões, provocações, alguns pequenos e breves deslocamentos acerca de como se aborda, geralmente, a obra literária em sala de aula com jovens. Destaco o quão essencial é pensar o ensino de literatura pautado no letramento literário, justamente para ultrapassar os simulacros da leitura como lastros de si mesma e reconhecer que a literatura pode "nos ajudar a ler melhor, não apenas porque possibilita a criação do hábito da leitura [...] mas sim [...] porque nos oferece [...] os instrumentos necessários para conhecer e articular com proficiência o mundo feito linguagem" ${ }^{20}$ Ler melhor na escola é, sem dúvida, ler melhor em outros espaços da vida, onde a literatura está sempre à espreita e à procura de novos ouvintes e leitores do que tem a dizer, provocando-os a enunciar o mundo a cada pacto firmado com os textos literários.

\section{IN.CONCLUSÕES}

O debate sobre as relações entre literatura e ensino no Brasil não é novo. Dos a nos 1980 até hoje, fins da segunda década do século XXI, as produções em torno do tema e
20. COSSON. Círculos de leitura e letramento literário, p. 30. 
21. Para maiores informações, ver resultados da PNAD, Pesquis Nocional por Amostra de Domicilios, no que se refere ao 2017, divulgados pelo Instituto Brasileiro de Geografia e Estatística (IBGE): < https://agenciadenoticias. ibge.gov.br/agencia-noticias/2012agencia-de-noticias/noticias/21255analfabetismo-cai-em-2017-massegue-acima-da-meta-para-2015>. seus desenraizamentos têm crescido substancialmente, fato revelador de que cada vez mais professores e pesquisadores têm se dedicado a um assunto tão importante e urgente num país com índices de analfabetismo extremos e milhões de pessoas ${ }^{21}$ incapazes de usar a leitura e a escrita como a rmas políticas e capital cultural. Porém, é observável certa distância dos estudos literários e da crítica literária quanto aos territórios pedagógicos, simbolizada, por exemplo, na ausência de linhas de pesquisa dedicadas ao ensino de literatura nos programas de pós-graduação em letras das IES brasileiras.

Um país não se faz com homens e livros, principalmente no caso do Brasil, que não é para principia ntes, como disse acertadamente Tom Jobim. Para construir um país de leitores, precisamos de diferentes identidades em trânsito, em devir, num estado próximo ao nomadismo, ca minhando em direções diversas que busquem como ponto de encontro a minimização das desigualdades sociais, econômicas e epistêmicas que excluem cruelmente milhões de brasileiros da experiência literária diversa como direito, do mercado editorial, dos prêmios literários e da vida cultural mais a mpla. Para construir efetivamente um Brasil de leitores precisamos dar visibilidade, ler e incentivar a produção literária afro-brasileira, legitimando e reconhecendo outras existências, histórias e narrativas que contrastem e contestem escritas e vozes unívocas e circunscritas à histórica única, já denunciada pela escritora nigeriana Chimamanda Ngozi Adichie em conferência realizada nos Estados Unidos, como marca de apagamentos ativamente produzidos e propulsora de estereótipos cristalizados culturalmente.

Penso que não é possível a literatura formar, sozinha, cidadãos. Para que ela exerça sua potência são necessárias condições plenas e igualitárias de cidadania, sem as quais as possibilidades concretas de edificar legiões de leitores críticos, sensíveis, perspicazes e capazes de modificar a si e ao mundo, diminuem consideravelmente e, em alguns casos, a té se a nulam. É bem verdade que há fissuras no tecido social que permitem a emergência de sujeitos que se formam leitores literários em situações adversas, mas negar o peso dos grilhões das violências sociais, raciais e de gênero e das desigualdades estruturais, que estão nas raízes da constituição nacional, no condicionamento de inúmeras histórias de vida, é se colocar diante do mundo incapaz de interrogá-lo, de enunciá-lo, de reelaborá-lo, de sonhá-lo maior e melhor (por que não?) para quem ainda é privado da força dessa arte que pode nos tornar menos inertes frente aos desafios e paradoxos da vida.

Insistir no ensino de literatura na educação básica, único espaço de formação literária para a maioria esmagadora

\begin{tabular}{|c|c|c|}
\hline EM TESE & BELO HORIZONTE & v. 24 \\
\hline
\end{tabular}


dos jovens brasileiros, é um dever de todo professor e pesquisador responsável socialmente e minimamente comprometido com a transformação social e a democratização de um bem que não é luxo, exclusividade de uns poucos iniciados ou torre de marfim dos eruditos. É um direito de todas as brasileiras, de todos os brasileiros e, como tal, precisa ser respeitado e fortalecido. A literatura é corpo-político, corpo-artístico, corpo-revolução, corpo-direito.

\section{REFERÊNCIAS}

ADICHIE, Chimamanda Ngozi. O perigo da história única. 2012. (18min49s). Disponível em: <https://www.youtube.com/ watch?v=EC-bh1YARsc > . Acesso em: 02 maio 2018.

BARRETO, Lima. O Triste Fim de Policarpo Quaresma. São Paulo: DCL, 2005

BARTHES, Roland. Aula. Trad. Leyla Perrone-Moisés. São Paulo: Cultrix, 1989

BARTHES, Roland. O prazer do texto. 6. Ed. São Paulo: Perspectiva, 2013.

BOURDIEU, Pierre As regras da arte: gênese e estrutura do campo literário. São Paulo: Companhia das Letras, 1996.

BRASIL. Base Nacional Comum Curricular - Ensino Médio: MEC, Secretaria da Educação Básica, 2017.
BRASIL. Lei no 9496, de 20 de dezembro de 1996. Estabelece as diretrizes e bases da educação nacional. Diário Oficial da República Federativa do Brasil. Brasília, DF. Disponível em: $<$ http://www.planalto.gov.br/ccivil 03/LEIS/L9394.htm>. Acesso em: 01 set. 2018

\section{BRASIL Orientações Curriculares para o Ensino Médio:}

linguagens, códigos e suas tecnologias. Brasília: MEC, Secretaria da Educação Básica, 2006.

BUTLER, Judith. Problemas de gênero: feminismo e subversão da identidade. Trad. Renato Aguiar. Rio de Janeiro: Editora Civilização Brasileira, 2003

CANDIDO, Antonio. O direito à literatura. In: Vários escritos. Rio de Janeiro: Ouro sobre Azul, 2011.

CASTANHEIRA, Maria Lúcia; GREEN, Judith. DIXON, Carol. Práticas de letramento em sala de aula: uma análise de ações letradas como construção social. Revista Portuguesa de Educação, v. 20, n. 2, p. 7-38, 2007.

CHICO BUARQUE. Construção. Cidade: Philips Records: 1971. $\mathrm{CD}(4 \mathrm{~min} 4 \mathrm{~s})$.

CHIQUINHA GONZAGA. Lauro César Muniz e Marcílio Moraes. São Paulo (SP). Rede Globo, 2008, DVD (Volumes 1 a 6).

Minissérie exibida na televisão entre os dias 12 de janeiro e 19 de março de 1999.

COMPAGNON, Antoine. Literatura para quê? Belo Horizonte: Editora UFMG, 2009 
COSSON, Rildo. Círculos de Leitura e Letramento Literário. São Paulo: Contexto, 2014

COSSON, Rildo. Letramento literário: teoria e prática. São Paulo: Contexto, 2006

DALVI, Maria Amélia. Literatura na escola: propostas didáticometodológicas. In: DALVI, Maria Amélia et al. Leitura de Literatura na Escola São Paulo: Parábola, 2013, p. 67-97.

DELEUZE, Gilles. Crítica e Clínica. São Paulo: Editora 34, 1997.

DERRIDA, Jacques. A Estrutura, o signo e o jogo no discurso das ciências humanas. In: DERRIDA, Jacques. A Escritura e a Diferença. Trad. Maria Beatriz Nizza da Silva. 4. Ed. São Paulo: Perspectiva. 2009. P. 407-426.

DERRIDA, Jacques. Essa estranha instituição chamada literatura: uma entrevista com Jacques Derrida. Trad. Marileide Dias Esqueda. Belo Horizonte: Editora UFMG, 2014

DERRIDA, Jacques. Signature, Event, Context. In: KAMUF, Peggy A Derrida Reader. Columbia University Press, New York: 1991, p. 80-111.

DERRIDA. A escritura e a diferença. São Paulo: Perspectiva, 2009.

DUARTE, Constância Lima. Feminismo e literatura no Brasil. Estudos Avançados, v. 17, n. 49, p. 151-172, 2003

DUARTE, Eduardo de Assis. Literatura afro-brasileira: um conceito em construção. In: Estudos de Literatura Brasileira Contemporânea, v. 1, p. 11-24, 2008.
DUARTE, Eduardo de Assis; FONSECA, Maria Nazareth Soares Orgs.). Literatura e Afrodescendência no Brasil: antologia crítica. Belo Horizonte: UFMG, 2011. Volumes 1 a 4.

EVARISTO, Conceição. Becos da memória. Belo Horizonte: Mazza, 2006.

FOUCAULT, Michel. A arqueologia do saber. 7. Ed. Trad. Luiz Felipe Baeta Neves. Rio de Janeiro: Forense Universitária, 2008.

FREIRE, Paulo. A importância do ato de ler: em três artigos que se completam. São Paulo: Cortez, 1988

FREIRE, Paulo. Pedagogia do Oprimido. 50. Ed. São Paulo: Paz e Terra, 2011.

GUIMARAENS, Alphonsus de. Ismália. 2. Ed. São Paulo: Cosac Naify, 2014.

HALL, Stuart. Da Diáspora: Identidades e Mediações Culturais. Trad. Adelaine La Guardia Resende. Belo Horizonte: Editora UFMG, 2003

JOUVE, Vincent. Por que estudar literatura? São Paulo: Parábola, 2012

ARROSA, Jorge. Sobre la experiência. Aloma: revista de psicologia, ciències de l'educació i de l'esport Blanquerna, Barcelona, p. 87-112, 2006

LARROSA, Jorge. Tremores: escritos sobre experiência. Belo Horizonte: Autêntica, 2015
EM TESE
BELO HORIZONTE
v. 24
N. 1
JAN.-ABR. 2018
MELO. 0 direito à literatura na escola: provocaç̧ões e outros quefazeres 
MACUNAIMMA. Direção e Produção: Joaquim Pedro de Andrade. Brasília (DF). Ministério da Cultura, 1969. Disponível em:

$<$ https://www.youtube.com/watch?v=XoyYFumkOqU>. Acesso em: 02 de maio de 2018

MAUÁ - O IMPERADOR E O REI. Direção: Sérgio Rezende. Produção: Joaquim Vaz de Carvalho. São Paulo (SP). Europa Filmes, 1999. Disponível em: <https://www.youtube.com/ watch? $v=$ tsNFt6oklxs $>$. Acesso em: 02 de maio de 2018.

MUNANGA, Kabengele. Rediscutindo a mestiçagem no Brasil identidade nacional versus identidade negra. Petrópolis, Rio de Janeiro: Vozes, 2004

MUNANGA, Kabengele; GOMES, Nilma Lino (Orgs.). 0 negro no Brasil de hoje. São Paulo: Global, 2006.

PAULINO, Graça; COSSON, Rildo. Letramento literário: para viver a literatura dentro e fora da escola. In: ZILBERMAN, Regina: RÖSING, Tania (Orgs.). Escola e leitura: velha crise; novas alternativas. São Paulo: Global, 2009

PROUST, Marcel. Em busca do tempo perdido. Trad. Fernando Py. Rio de Janeiro: Ediouro, 2002.

RAMOS, Graciliano. Infância. Rio de Janeiro/São Paulo: Record Atalaya, 1995.

RIBEIRO, João Ubaldo. Viva o povo brasileiro. Rio de Janeiro: Alfaguara Brasil, 2008
ROUXEL, Annie. Aspectos metodológicos do ensino da literatura. In: DALVI, Maria Amélia. et al. Leitura de Literatura na Escola. São Paulo: Parábola, p. 17-34, 2013.

STEINER, George. Lenguaje y silencio: ensayos sobre la literature, el inguaje y lo inhumano. Barcelona: Gedisa, 1994.

TRISTE FIM DE POLICARPO QUARESMA. Direção: Paulo Thiago. Produção: Gláucia Camargos. Brasília (DF). Ministério da Cultura, 1998. Disponível em: <https://www.youtube.com/ watch $\mathrm{v}=\mathrm{mSSTpFHI3J0}>$. Acesso em: 02 de maio de 2018.

WITTGENSTEIN, Ludwig. Tractatus lógico-philosophicus. Paris: Gallimard, 1993.

Recebido: 08/06/2018 Aceito: 18/09/2018 